\title{
Endovascular Bariatric Surgery as Novel Minimally Invasive Technique for Weight Management in the Morbidly Obese: Review of the Literature
}

\author{
Giuseppe Massimo Sangiorgi ${ }^{1, *} \mathbb{C}$, Alberto Cereda ${ }^{2}$, Nicola Porchetta ${ }^{1} \mathbb{D}$, Daniela Benedetto ${ }^{1}$, \\ Andrea Matteucci ${ }^{1}{ }^{\circledR}$, Michela Bonanni ${ }^{1}{ }^{\circledR}$, Gaetano Chiricolo ${ }^{1}$ and Antonino De Lorenzo ${ }^{1} \mathbb{D}$
}

1 Department of Biomedicine and Prevention, Institute of Cardiology, Cardiac Cath Lab, University of Rome Tor Vergata, 00133 Rome, Italy; nicola.porchetta@gmail.com (N.P.); dania.benedetto@gmail.com (D.B.); andrea.matteucci2@gmail.com (A.M.); michelabonanni91@gmail.com (M.B.); gaetano.chiricolo@ptvonline.it (G.C.); delorenzo@uniroma2.it (A.D.L.)

2 Department of Cardiology, Cardiac Cath Lab, San Gaudenzio Clinic, 28100 Novara, Italy; tskcer@hotmail.it

* Correspondence: gsangiorgi@gmail.com

\section{check for}

updates

Citation: Sangiorgi, G.M.; Cereda, A.; Porchetta, N.; Benedetto, D.;

Matteucci, A.; Bonanni, M.; Chiricolo,

G.; De Lorenzo, A. Endovascular

Bariatric Surgery as Novel Minimally

Invasive Technique for Weight

Management in the Morbidly Obese:

Review of the Literature. Nutrients

2021, 13, 2541. https://doi.org/

$10.3390 /$ nu13082541

Academic Editor: Ina Bergheim

Received: 30 May 2021

Accepted: 21 July 2021

Published: 25 July 2021

Publisher's Note: MDPI stays neutral with regard to jurisdictional claims in published maps and institutional affiliations.

Copyright: (c) 2021 by the authors. Licensee MDPI, Basel, Switzerland. This article is an open access article distributed under the terms and conditions of the Creative Commons Attribution (CC BY) license (https:// creativecommons.org/licenses/by/ $4.0 /)$.

\begin{abstract}
Nowadays, obesity represents one of the most unresolved global pandemics, posing a critical health issue in developed countries. According to the World Health Organization, its prevalence has tripled since 1975 , reaching a prevalence of $13 \%$ of the world population in 2016 . Indeed, as obesity increases worldwide, novel strategies to fight this condition are of the utmost importance to reduce obese-related morbidity and overall mortality related to its complications. Early experimental and initial clinical data have suggested that endovascular bariatric surgery (EBS) may be a promising technique to reduce weight and hormonal imbalance in the obese population. Compared to open bariatric surgery and minimally invasive surgery (MIS), EBS is much less invasive, well tolerated, with a shorter recovery time, and is probably cost-saving. However, there are still several technical aspects to investigate before EBS can be routinely offered to all obese patients. Further prospective studies and eventually a randomized trial comparing open bariatric surgery vs. EBS are needed, powered for clinically relevant outcomes, and with adequate follow-up. Yet, EBS may already appear as an appealing alternative treatment for weight management and cardiovascular prevention in morbidly obese patients at high surgical risk.
\end{abstract}

Keywords: bariatric surgery; cardiovascular disease; endovascular bariatric surgery; obesity; prevention

\section{Introduction}

Nowadays, obesity represents one of the most unresolved global pandemics, posing a critical health issue in developed countries. According to the World Health Organization, its prevalence has tripled since 1975 , reaching $13 \%$ of the world population in 2016 . Obesity is defined as a body mass index (BMI) greater than $30 \mathrm{~kg} / \mathrm{m}^{2}$, while morbid obesity is defined as BMI $>40 \mathrm{~kg} / \mathrm{m}^{2}$. Numerous comorbidities such as major stroke, acute myocardial infarction, hypertension, type 2 diabetes, hyperlipidemia, obstructive sleep apnea, and all-cause mortality are strongly associated with this disease [1]. As a result, approximately 2.8 million deaths per year may occur in adult populations affected by obesity.

Given the tremendous impact on public health with an approximate attributable cost of nearly 150 billion dollars per year in the United States, obesity treatments have become of critical importance for the healthcare system, the medical community, and policymakers [2].

The cornerstone of obesity treatment is represented by behavioral modifications (i.e., diet and physical exercise), ideally in a highly motivated patient that should be followed by a multidisciplinary team of healthcare professionals. If successful, this strategy consents modest and durable weight loss reduction of 5\% to $10 \%$ [3]. The long-term efficacy of all behavioral therapies is limited. For those unable to reach these goals, few drugs (orlistat, lorcaserin, phentermine/topiramate, nartrexone/bupropion, semaglutide and liraglutide) 
are available as adjuvant therapy, but in general, are not free of side effects, usually dosedependent, have limited adherence (frequently due to arbitrary withdrawal of the drug), and with suboptimal outcome in obtaining the goal of weight-reduction. Recently, nonsurgical endoscopic bariatric therapies such as intragastric balloons, endoscopic gastric plication, and endoluminal duodenal-jejunal sleeve have been implemented in patients not willing to undergo conventional bariatric surgery. However, potentially severe complications have been reported with these techniques (gastric perforation, bowel obstruction, and gastrointestinal bleeding), and for these reasons they are currently performed only in highly experienced centers.

Surgical approaches, mainly represented by Roux-en-Y gastric bypass, adjustable gastric banding, sleeve gastrectomy, and biliopancreatic division (Figure 1) are reserved to morbidly obese individuals or obese individuals with one or more obesity-related comorbidities (or even lower for uncontrolled diabetes) who have not been able to reach the aforementioned goals with behavioral modifications and drug therapy.

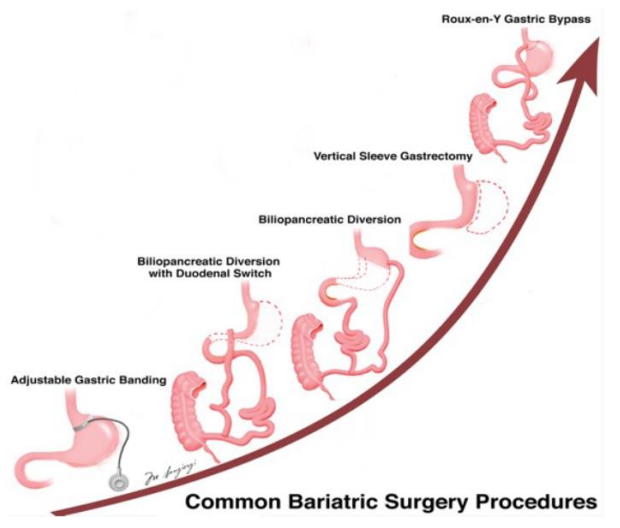

Figure 1. Overview of different bariatric surgery options. The most effective options in weight reduction are the Roux-en-Y gastric bypass and sleeve gastrectomy. Arrow indicates an increase in efficacy.

Well-known short- and long-term complications, even if uncommon, including bleeding, infections, deep venous thrombosis, gastric dumping syndrome, and internal hernia have been reported with different surgical techniques.

Another frequent eventuality is post-bariatric surgery anemia: it is in most cases due to iron deficiency, along with vitamin B12 deficiency as a secondary cause. Iron deficiency is expressed by low serum ferritin and it occurs because of its lower absorption secondary to hypocloridria and the bypassing of the duodenum and proximal jejunum [4]. In addition to anemia, vitamin B12 deficiency (resulting from inadequate secretion of intrinsic factor, limited gastric acidity and the bypassing of the duodenum) can lead to neurological disorders [4]. In the absence of adequate vitamin B12 supplement, up to 30\% of patients will be unable to maintain normal levels of plasma B12 at 1 year [5].

Bariatric surgery results in calcium/vitamin D malabsorption (results from bypassing the duodenum and proximal jejunum) with secondary hyperparathyroidism, changes in fat mass and alterations in fat- and gut-derived hormone; the final effect is an accelerated bone loss [4]. Patients affected by secondary hyperparathyroidism should obtain bone benefits from oral supplementation of vitamin D [5,6]. In fact, the European Association for Endoscopic Surgery (EAES) Clinical practice guidelines on bariatric surgery strongly recommend vitamin D supplement post-surgery because the anticipated benefits outweigh the potential risks of vitamin therapy [7].

Poor protein digestion and absorption, secondary to altered biliary and pancreatic function, is involve in protein malnutrition and can be observed after bariatric surgery [4]; albumin levels can be considered as marker of protein deficiency [6].

Low serum levels of fat-soluble vitamins (vitamin A, K and E) usually occur after bariatric procedure $[4,5]$. 
As a "treatment gap" option, a novel minimally invasive procedure, i.e., endovascular embolization of the gastric fundus arterial supply (endovascular bariatric surgery -EBS), has been proposed as a supplementary technique with successful results in animal models and a few recently published small clinical trials [8-13].

We report herein an updated review on the rational, pathophysiology, experimental, and clinical outcomes with this procedure in obese patients.

\section{Pathophysiological Basis for EBS}

Gastric fundus is mainly supplied by the left gastric artery (LGA) and sometimes by the gastroepiploic artery. The stomach has a neurohumoral role on hunger regulation through ghrelin: this is the rationale for gastric fundus embolization. Ghrelin is a ligand of the growth hormone secretagogue receptor (GHS-R) in neuropeptide Y (NPY) and agoutirelated peptide (AgRP) in the arcuate nucleus of the hypothalamus with a downstream effect to inhibit the release of the $\alpha$-melanocyte-stimulating hormone. Therefore, ghrelin acts to increase appetite and food intake, increasing weight gain (Figure 2). Practically, ghrelin plasma level rises sharply shortly before meals, which correlates with hunger sensation that occurs before consuming food. Conversely, ghrelin falls immediately after eating, which correlates with the sense of satiation after eating [14,15]. In addition, ghrelin downregulates anorexigenic hormone receptors for PYY, GLP-1, and cholecystokinin and reduces the sensitivity of gastric distension by selectively inhibition of gastric subpopulation of mechanically sensitive vagal afferent nerves $[16,17]$. Nearly $90 \%$ of body ghrelin is produced in the ghrelin-secreting cells of the stomach, mainly in the gastric fundus with fewer amounts produced in the small intestine, brain, and pancreas. Therefore, the main goal of the EBS procedure is to reduce ghrelin production by the stomach.

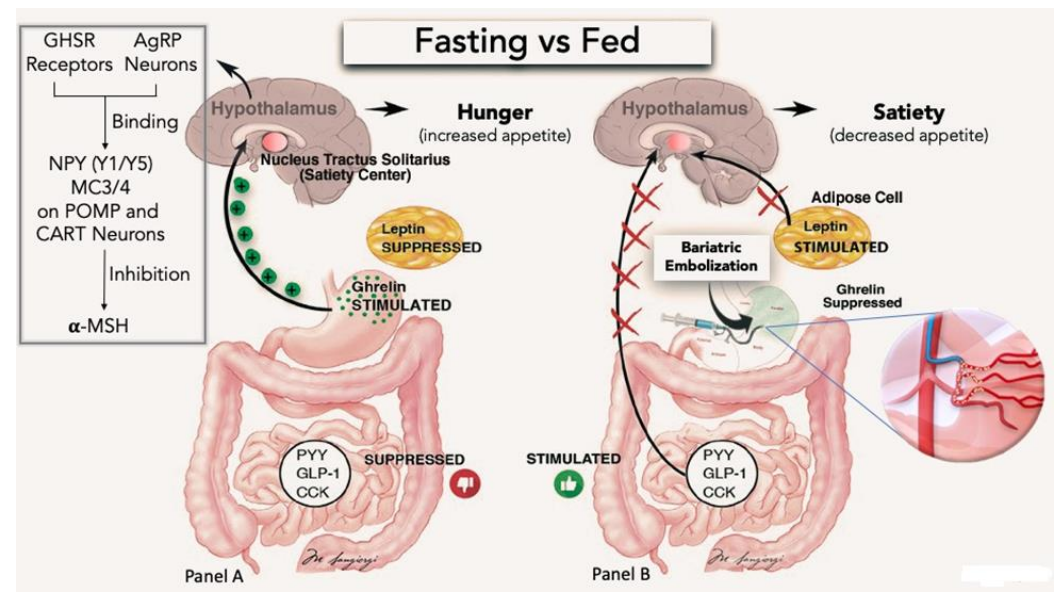

Figure 2. Hormonal changes and diagram of the ghrelin signal pathway. (A) The "hunger hormone" ghrelin is secreted by the gastric fundus, whereas peptide YY (PPY), cholecystokinin (CCK), and glucagon-like peptide (GLP-1) are secreted in the gut from L cells. Adipocytes produce leptin (LPT). In the fasting state, decreased food intake suppresses the release of PPY, GLP-1, CCK, and LPT, while stimulates ghrelin production from the stomach. Ghrelin binds in the hypothalamic arcuate nucleus to growth hormone secretagogue receptor (GHSR) in neuropeptide Y (NPY) and agouti-related peptide (AgRP) neu-rons. NPY and AgRP bind subsequently to NPY subtype 1 and 5 (NPH Y1/Y5) and melacortin-3 and-4 (MC3/4) receptors on proopiomelanocortin (POMP) and cocaine-amphetamineregulated transcript neurons (CART), inhibiting the release of $\alpha$ - melanocyte-stimulating hormone ( $\alpha$-MSH). By inhibiting $\alpha-\mathrm{MSH}$, ghrelin acts to increase hunger and food intake. (B) BES procedure reducing ghrelin production in the stomach fundus area, mimics a fed state characterized by PYY, GLP-1, CCK, and LPT hormone increases. As a result, appetite decreases and an increase in the feeling of satiety occurs. 
It has been previously reported in small retrospective studies $[18,19]$ that patients with gastrointestinal bleeding treated with LGA embolization had significant weight loss after the procedure. Although these studies are difficult to interpret due to the small sample size, associated comorbidities, high-risk profile of the population included, and variable follow-up, they proved the concept and set the basis for gastric fundus embolization as a possible treatment for obesity.

\section{EBS Procedure}

The celiac trunk branches from the aorta at the level of the twelfth thoracic vertebra (T12). The LGA is the first and smaller branch of the celiac trunk, even if there are less common possibilities of independent origins from the aorta, splenic artery, common hepatic artery, gastroduodenal artery and superior mesenteric artery. It runs along the superior portion of the lesser gastric curvature and anastomoses with the right gastric artery that arises from the common hepatic artery. The left gastroepiploic artery (GEA) is the largest branch of the splenic artery and gives gastric branches to both surfaces of the stomach. It anastomoses with the right GEA that arises from the gastroduodenal artery (Figure 3). Normal anatomic variants are frequent and can be present in up to $30 \%$ of patients.

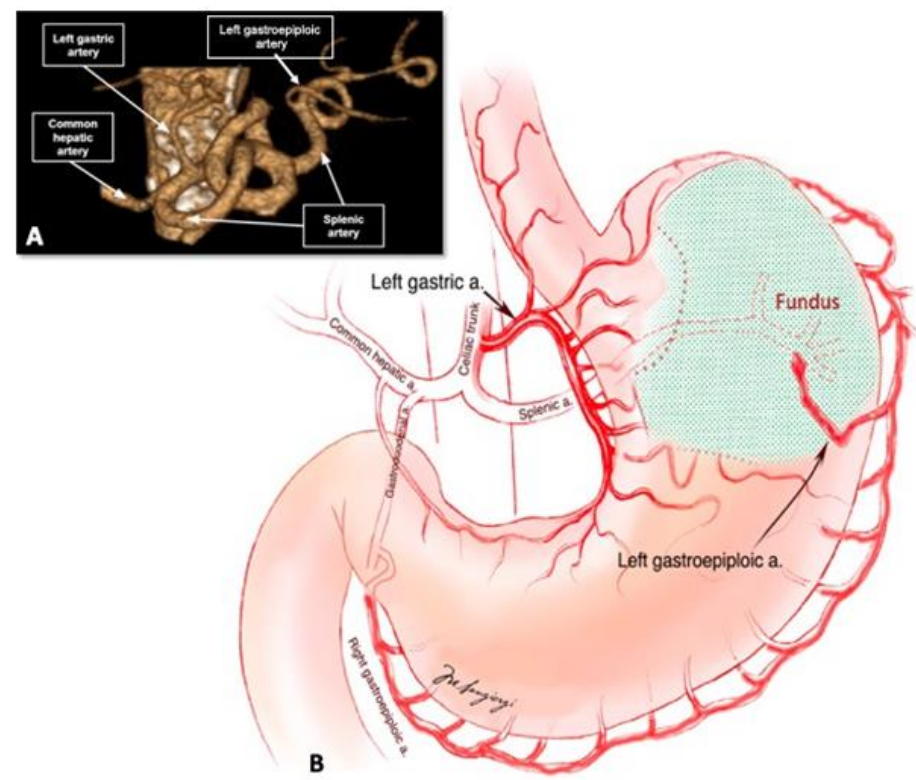

Conventional Gastric Arterial Anatomy and Target Vessels for Bariatric Embolization

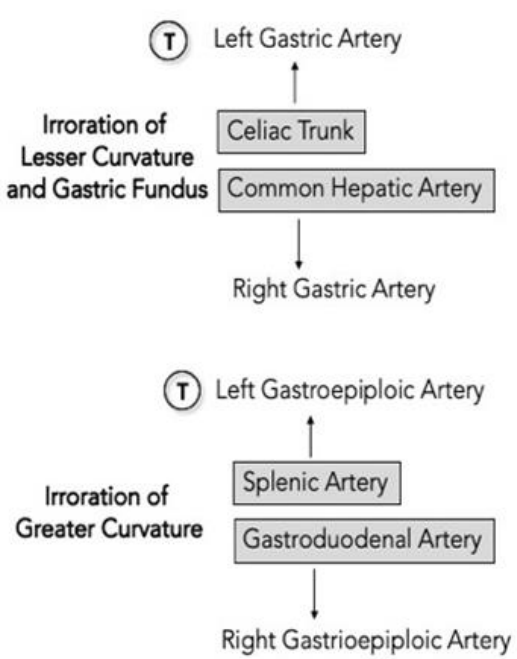

Figure 3. Voxel Gradient Angio-CT 3D reconstruction (A) and schematic drawn (B) of left gastric artery and left gastroepiploic artery normal anatomy. Most commonly the left gastric artery originates from the celiac trunk. Less frequently, the artery may arise directly from the aorta, splenic artery, common hepatic artery, and superior mesenteric artery. The superior part of the greater curvature of the stomach is supplied by the left gastroepiploic artery while the inferior part of the greater curvature by the right gastroepiploic artery. T indicates target for BES procedure.

Although there is no standard bariatric embolization procedure, similar approaches have been used in the majority of studies done so far. Through the femoral or radial artery, a selective digital subtraction angiography (usually in $\mathrm{AP}, \mathrm{LAO} 60^{\circ}$, or $\mathrm{LAO} 90^{\circ}$ projections) of the celiac trunk is performed to identify the LGA and other potentials embolization targets (all arteries supplying the gastric fundus and potential accessory gastric arteries); the decision to embolize other vessels, especially the gastroepiploic artery, is based on their contribution to fundal blood supply (assessed angiographically). Different types of diagnostic catheters can be used for this purpose (JR, Simons, Cobra, SOS, among others) depending on the operator's preference and experience. Cone beam CT has also been used by some authors for best determining fundal perfusion and the eventual need to embolize other arterial territories. After targets have been identified, selective cannulation and 
angiography using the same catheter or a microcatheter are performed. Embolic material choice has been variable throughout trials with $300-500 \mu \mathrm{m}$ and $500-700 \mu \mathrm{m}$ microspheres and $300-500 \mu \mathrm{m}$ or $500-700 \mu \mathrm{m}$ polyvinyl alcohol (PVA) particles used. LGA embolization can also be performed with an occlusion balloon microcatheter (OBC) advanced into the target artery over a standard guidewire: a subsequent balloon inflation at the $\mathrm{OBC}$ tip can be used to prevent retrograde reflux, with tip pressure/resistance monitored to prevent overembolization and antegrade reflux. Embolization is taken to stasis, which was defined as the visual absence of the flow of contrast after five heartbeats; postembolization DSA is usually acquired to confirm the success of embolization (Figure 4). Unfortunately there are no consensus statements to standardize this procedure.
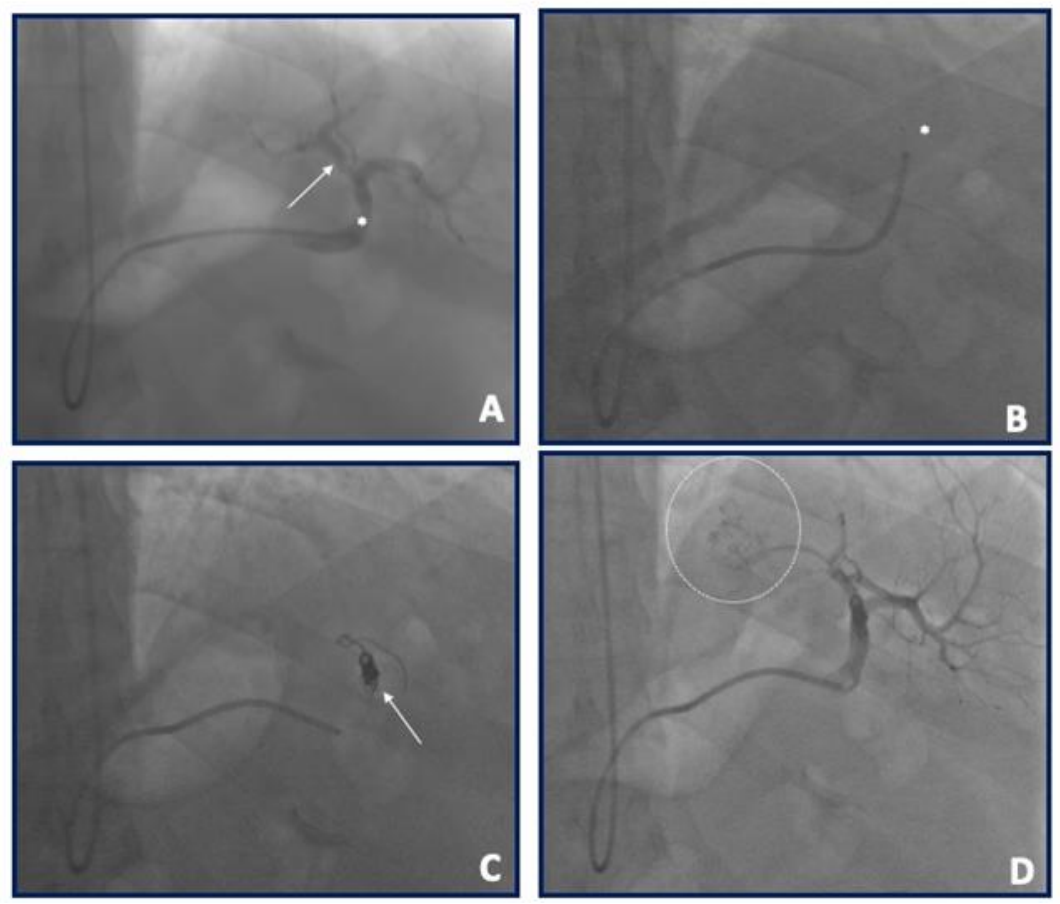

Figure 4. Case example of a left gastroepiploic artery (arrow) embolization in a 55 years old male with a BMI of 43.2. (A) Selective angiography by multipurpose $6 \mathrm{~F} 125 \mathrm{~cm}$ into the splenic artery (asterisk). (B): A Rebar $0.27^{\prime}$ microcatheter (Medtronic, Santa Rosa, CA, USA-asterisk) was advanced into the multipurpose catheter selectively engaging the gastroepiploic artery. (C) Three contour spirals (Medtronic, Santa Rosa, CA, USA) of different size and length ( $4 \times 40 \mathrm{~mm} ; 4 \times 40 \mathrm{~mm} ; 5 \times 30 \mathrm{~mm}$ ) were subsequently released (arrow). (D) Final angiography with target fundus zone indicated by dashed circle.

\section{EBS Preclinical Evidence}

In 2007, Arepally and coauthors published the first experience of catheter embolization of the LGA to reduce systemic plasma levels of ghrelin in a swine model [20]. The study showed a reduction in ghrelin but no significant weight change. Micro-ulcers at the gastroesophageal junction were also observed in the euthanized animals. A follow-up study with a sham procedure in the control group evaluated ghrelin levels and natural weight gain in 4 weeks follow-up. A significant decrease in weight $(7.8 \%)$ compared to the control group (15.1\%) was shown [21].

In a canine model, Bawudun et al. [22] showed a significant decrease in plasma levels of ghrelin, abdominal subcutaneous fat, and body weight in Lipiodol-embolized (or a combination of Lipiodol and polyvinyl-alcohol) animals compared to control group. Peak effect was obtained between weeks three and four and compensatory rise in plasma levels of ghrelin was observed at seven weeks after embolization. According to the author, this 
result may suggest the compensatory production of ghrelin that occurred in the gastric fundus after the embolization.

Paxton and colleagues obtained $55 \%$ of ghrelin reduction associated with significant weight loss at eight weeks in a swine model using $40 \mu \mathrm{m}$ microsphere as embolizing agent [23]. The same author evaluated by histology the gastric mucosa of swine after the procedure and demonstrated healed or healing ulcers in $50 \%$ of the gastric body of treated animals [24].

In 2016, to assess whether the number of fundal arteries embolized could impact the ghrelin reduction and gastric ulceration rate, the same authors utilized embolic microspheres into four arteries supplying the gastric fundus, vs. two arteries vs. one artery. Only the group of swine undergoing complete embolization demonstrated significant ghrelin reduction compared to sham control animals. Gastric ulcers were present in $50 \%$ of animals that embolized four arteries compared to $40 \%$ in the other groups [25].

In 2017, Kim et al. [26] performed EBS in five swine by selectively infusing 50-150 or 150-250 $\mu \mathrm{m}$ PVA particles into the gastric arteries while five animals were treated with saline infusion as a sham procedure. Endoscopy was performed three weeks after EBS to see whether any gastric ulcer occurred. Celiac trunk angiography was performed eight weeks after EBS [27]. No statistically significant differences in ghrelin levels were observed after eight weeks despite a reduction compared to the control group. In the embolized group, ulcerations were identified in three animals $(60 \%)$. Re-canalization of the embolized arteries was identified on follow-up angiography in three animals $(60 \%)$, respectively, suggesting that EBS procedure with PVA particles can transiently suppress ghrelin levels in embolized animals. However, ulcerations of gastric fundus and recanalization of the embolized arteries are present in the long-term follow-up.

A comparison of the studies involving animal models is reported in Table 1.

Table 1. Experimental studies evaluating BES procedure for weight reduction.

\begin{tabular}{|c|c|c|c|c|c|}
\hline Author/Year/REF. & Animal Model & $\mathbf{N}$ of Animals & Follow-Up & $\begin{array}{l}\text { Absolute Weight } \\
\text { Change (\%) }\end{array}$ & $\begin{array}{c}\text { Absolute Ghrelin } \\
\text { Change (\%) }\end{array}$ \\
\hline Arepally 2007 [20] & Swine & $\begin{array}{c}5 \\
2 \text { CTRL } \\
4 \text { LDSM } \\
4 \text { HDSM }\end{array}$ & 4 weeks & $\begin{array}{l}8.6 \text { increase } \\
1.4 \text { increase } \\
1.4 \text { increase }\end{array}$ & $\begin{array}{c}15 \% \text { increase } \\
130 \% \text { increase } \\
60 \% \text { decrease }\end{array}$ \\
\hline Arepally 2008 [21] & Swine & $\begin{array}{c}10 \\
5 \text { CTRL } \\
5 \text { SM }\end{array}$ & 4 weeks & $\begin{array}{l}15.8 \text { increase } \\
7.8 \text { increase }\end{array}$ & $\begin{array}{l}10.1 \text { increase } \\
12.9 \text { decrease }\end{array}$ \\
\hline Bawudun 2012 [22] & Dog & $\begin{array}{c}15 \\
5 \text { CTRL } \\
5 \text { EO } \\
5 \text { PVA }\end{array}$ & 8 weeks & $\begin{array}{l}5 \text { increase } \\
5 \text { decrease } \\
10 \text { decrease }\end{array}$ & $\begin{array}{l}13.6 \text { increase } \\
15.8 \text { decrease } \\
30.1 \text { decrease }\end{array}$ \\
\hline Paxton 2013 [23] & Swine & $\begin{array}{c}12 \\
6 \mathrm{CTRL} \\
6 \mathrm{MS}\end{array}$ & 8 weeks & $\begin{array}{l}28 \text { increase } \\
10 \text { increase }\end{array}$ & $\begin{array}{l}30 \text { increase } \\
30 \text { decrease }\end{array}$ \\
\hline Paxton 2014 [24] & Swine & $\begin{array}{c}12 \\
6 \mathrm{CTRL} \\
6 \mathrm{EO}\end{array}$ & 8 weeks & $\begin{array}{l}\text { Not Reported } \\
\text { Not Reported }\end{array}$ & $\begin{array}{l}\text { Not Reported } \\
\text { Not Reported }\end{array}$ \\
\hline Paxton 2016 [25] & Swine & $\begin{array}{c}22 \\
6 \text { CTRL } \\
6 \text { EA [8]5 EA [2]5 } \\
\text { EA [1] }\end{array}$ & $4-8$ weeks & $\begin{array}{c}26.5 \text { increase } \\
8.7 \text { increase } \\
19.7 \text { increase } \\
23.0 \text { increase }\end{array}$ & $\begin{array}{l}19.9 \text { increase } \\
29.9 \text { decrease } \\
18.2 \text { increase } \\
234 \text { increase }\end{array}$ \\
\hline Kim 2017 [26] & Swine & $\begin{array}{c}10 \\
5 \text { CTRL } \\
5 \text { PVA }\end{array}$ & $2 \operatorname{mos}$ & $\begin{array}{l}30 \% \text { increase } \\
27 \% \text { increase }\end{array}$ & $\begin{array}{l}\text { No change } \\
40 \% \text { decrease }\end{array}$ \\
\hline
\end{tabular}

CTRL = control; LDSM = low dose sodium morrhuate; HDSM = high dose sodium morrhuate; EO = ethiodized oil (Lipiodol); $\mathrm{PVA}=$ polyvinyl-alcohol; $\mathrm{MS}=$ microspheres; $\mathrm{EA}(n)=$ number of embolized arteries . 


\section{EBS Human Clinical Evidence}

The available clinical evidence on bariatric embolization has been thoroughly described in previous reports $[10,27,28]$. The first human experience was published in 2013 by Kipshidze and colleagues [11] with its two years follow-up published in 2015. In this five-patient series (mean age $44.7 \pm 7.4$ ), the average weight decreased from $128.1 \pm 24.4$ to $106 \pm 21$ at two years. All procedures were performed through femoral access using $6 \mathrm{~F} \mathrm{JR}$ 4 catheters for angiography and Excelsior 1018 Microcatheter (Boston Scientific Corp., Cork, Ireland) for selective cannulation. Embolization was done with 300 to $500 \mu \mathrm{m}$ embospheres (Biocompatibles UK Limited, Surrey, United Kingdom). There were no major procedural complications. Three of the five patients complained of abdominal discomfort after the procedure, all with unremarkable follow-up gastroscopies.

The GET LEAN trial [13] (Gastric Artery Embolization Trial for the Lessening of Appetite Nonsurgically) published in 2016 analyzed the safety and efficacy of LGA embolization at six months. With four patients included (mean age 41 years, range, 30-54), average weight loss was $9.2 \mathrm{~kg}$ (range 2.7-17.2) at six months follow-up. Ultrasound (US) guided right femoral or left radial access and 4-5 F Simmons 1 catheter for angiography were use and embolization was performed with 300 to $500 \mu \mathrm{m}$ microspheres through a microcatheter. No major complications were reported. Three of the five patients complained of mild nausea, occasional vomiting, and mild epigastric discomfort immediately following the procedure that were resolved within $24 \mathrm{~h}$ for two patients and within 3-4 days for the other.

In another series published by Bai [8] in 2018 that included five patients with a mean age of $42.8 \pm 13.9$, weight loss was on average $12.9 \pm 14.66 \mathrm{~kg}$ at nine months follow-up. Operators used US guided femoral access in all patients, $5 \mathrm{~F}$ standard catheter for angiography, Progreat 2, 7 F microcatheter (Terumo) for selective cannulation, and embolization was done with 500-710 $\mu \mathrm{m}$ PVA particles (COOK Incorporated, Bloomington). No major complications were reported: four patients experienced slight epigastric discomfort in the first hours after the procedure, which resolved within $48 \mathrm{~h}$. One patient developed a small ulceration (3 $\mathrm{mm}$ in length) below the cardia (grade II according to CTCAE v4.0), which endoscopically healed 30 days later after treatment with omeprazole $(20 \mathrm{mg})$.

Pirlet in 2019 [12] studied seven morbid-obese patients (mean age $48 \pm 7$ years, mean BMI of $52 \pm 8 \mathrm{~kg} / \mathrm{m}^{2}$ ) who were referred for coronary angiography. Weight loss was on average was $13 \pm 17 \mathrm{~kg}$ (median loss: $-11 \mathrm{~kg}[0,-25]$ ) at up to 12 months after the procedure. The procedures were done through 5-6F right radial access, and selective cannulation of the LGA was done by 5F JR catheter in all but one patient where a 3F Renegade Microcatheter (Boston Scientific Corp., Cork, Ireland) was used. Embolization with 300-500 $\mu \mathrm{m}$ PV particles (Cook Medical, Bloomington, Indiana, USA) was performed. No major complications were observed in this series. Six patients had transient epigastric discomfort resolved with pro-ton pump inhibitors (PPIs).

In a retrospective series published by Elens and colleagues [9] in 2019 that included 16 patients who underwent embolization of the LGA the mean weight loss was $8 \pm 5.12 \mathrm{~kg}$. The procedure was successful in all but one patient. Four patients $(25 \%)$ were lost in follow-up. Femoral access was used in all patients; celiac trunk angiogram was done with a 5F cobra catheter (Cook Medical, Bloomington, Indiana, USA), LGA angiography with 5F MP catheter, selective cannulation with Progreat 2.7F (Terumo, Tokyo, Japan) microcatheter and embolization was performed with 300-500 $\mu \mathrm{m}$ embospheres (Merit Medical) in the first patient and 500-700 $\mu \mathrm{m}$ embospheres in the remaining patients. The patient treated with 300-500 $\mu \mathrm{m}$ embosphere had gastric ulceration on control endoscopy that resolved at three months. One major complication was reported in this series of a patient that ended in the intensive care unit for pancreatitis, splenic infarct and late gastric perforation.

The BEAT trial [29] (Bariatric Embolization of Arteries for the Treatment of Obesity) 1-year results included 20 patients (mean age of 44 years $6+/-11$ years) and the procedure was successful in all of them. The mean excess weight loss at one year was $11.5 \%$ (95\% CI: $6.8 \%-16 \% ; p<0.001)$. In this series, patients underwent two-weeks pre-treatment 
with omeprazole and sucralfate that continued up to 6 weeks post-procedure. Operators used femoral access, celiac trunk angiography plus cone-beam CT to evaluate the gastric arterial distribution. Catheterization was performed with a 5-F SOS guiding catheter (Angiodynamics, Latham, NY), and a 2.9-F high-flow microcatheter (Maestro; Merit Medical) was utilized for selective cannulation. After administration of $200 \mathrm{mg}$ of nitroglycerin and $2.5 \mathrm{mg}$ of verapamil (only into the LGA), embolization was performed with $300-500 \mu \mathrm{m}$ embospheres (Merit Medical). No major complications were reported on this trial. Eleven minor adverse events occurred in eight participants. One participant had subclinical pancreatitis, evident by transient elevation of lipase levels during the hospital stay that was treated with supportive care and discharged within $48 \mathrm{~h}$, with no further clinical sequels.

Zaitoun and collaborators recently published a pilot study of EBS in 10 patients with obesity (BMI > $30 \mathrm{~kg} / \mathrm{m}^{2}$ ) and prediabetes (hemoglobin A1c (HbA1c) level 5.7\%-6.4\%) [30]. A statistically significant reductions in $\mathrm{HbA1c}$ (from $6.1 \% \pm 0.2$ to $4.7 \% \pm 0.6 ; p<0.0001$ ), mean body weight (from $107.4 \mathrm{~kg} \pm 12.8$ to $98 \mathrm{~kg} \pm 11.6 ; p<0.0001$ ), and mean BMI (from $37.4 \mathrm{~kg} / \mathrm{m}^{2} \pm 3.3$ to $34.1 \mathrm{~kg} / \mathrm{m}^{2} \pm 3 ; p<0.0001$ ) was observed at 6 months follow-up. Embolization was performed with $300-500 \mu \mathrm{m}$ microspheres. The authors also reported a significant positive correlation between BMI and HbA1c levels $(r=0.91 ; C I, 0.66-0.98$; $p=0.0002)$.

In 2020 the LOSEIT group, led by Vivek Reddy of the Icahn School of Medicine at Mount Sinai in New York City, published the first in-human, sham-controlled, randomized clinical trial about EBS [31]. In this trial 40 patients (BMI of 35.0 to $55.0 \mathrm{~kg} / \mathrm{m}^{2}$ and age 21 to 60 years) underwent randomization in 1:1 to either sham or transcatheter bariatric embolotherapy (TBE) targeting the left gastric artery; patients randomized to sham were unblinded at 6 months and crossover to TBE was allowed. Patients of both groups received a lifestyle support (diet and behavioral education for weight loss). TBE has been performed via femoral arterial access using standard 6-F guiding catheters for celiac artery angiography. In a case the gastroduodenal artery was the origin of the left gastric artery which supplied the gastric fundus and in one patient the embolization target vessel was the left hepatic artery. An occlusion balloon microcatheter (Endo-bar Solutions LLC, Orangeburg, New York) was advanced into the target artery and a balloon at the tip was inflated to prevent retrograde reflux. The embolization was achieved by using 300- to 500-mm microspheres (BeadBlock, Biocompatibles Ltd., Farnham, United Kingdom) into the LGA. The procedure was repeated until adequate angiographic stasis was achieved with the balloon deflated over 5 cardiac cycles. Patients randomized to sham received propofol only, without arterial access. At 6 months, in both the intention-to-treat and per-protocol populations, the total body weight loss was greater with TBE $(7.4 \mathrm{~kg} / 6.4 \%$ and $9.4 \mathrm{~kg} / 8.3 \%$ loss, respectively) than sham $(3.0 \mathrm{~kg} / 2.8 \%$ and $1.9 \mathrm{~kg} / 1.8 \%$, respectively; p $1 / 40.034 / 0.052$ and p $1 / 40.0002 / 0.0011$, respectively); the total body weight loss was maintained with TBE at 12 months (intention-to-treat $7.8 \mathrm{~kg} / 6.5 \%$ loss, per-protocol $9.3 \mathrm{~kg} / 9.3 \%$ loss; p 1/4 0.0011/0.0008, p 1/4 0.0005/0.0005, respectively). After 1 week, all the patients underwent endoscopic examination: 5 cases of asymptomatic ulceration in the treatment group occurred (4 small superficial ulcers in the sub-cardiac region of the stomach and 1 superficial ulcer in the greater curvature).

Bariatric Embolization of Arteries With Imaging Visible Embolics (BEATLES) (BAE2) is an on-going, randomized, sham-controlled study sponsored by Johns Hopkins University [32]. The aim of the trial, with an estimated enrollment of 59 participants, is to evaluate the change in body weight 12 months after randomization in the bariatric embolization procedure arm versus the control (sham) arm; the estimated study completion date is December 2023.

A comparison of the studies involving humans is reported in Table 2. 
Table 2. Clinical Studies Evaluating BES procedure for Weight Reduction.

\begin{tabular}{|c|c|c|c|c|c|}
\hline Author/Year/REF & Study Design & $\mathrm{N}$ of pts & Follow-UpLength & $\begin{array}{l}\text { Total Weight } \\
\text { Loss (\%) }\end{array}$ & Embolic Material \\
\hline Kipshidze 2015 [11] & Prospective & 5 & 2 years & $22 \mathrm{~kg}(17.1 \%)$ & $\begin{array}{c}\text { 300-500 } \mu \mathrm{m} \text { BeadBlock } \\
\text { embospheres }\end{array}$ \\
\hline GET-LEAN 2016 [13] & Prospective & 4 & 6 months & $9.2 \mathrm{~kg}(8.5 \%)$ & $\begin{array}{c}\text { 300-500 } \mu \text { m BeadBlock } \\
\text { embospheres }\end{array}$ \\
\hline Bai 2018 [8] & Prospective & 5 & 9 months & $12.9 \mathrm{~kg}(12.6 \%)$ & 500-710 $\mu \mathrm{m}$ PVA particles \\
\hline Pirlet 2019 [12] & Prospective & 7 & 12 months & $13 \mathrm{~kg}(4.7 \%)$ & 300-500 $\mu \mathrm{m}$ PVA particles \\
\hline Elens 2019 [9] & Prospective & 16 & 12 months & $8 \mathrm{~kg}(10 \%)$ & $\begin{array}{c}\text { 500-700 } \mu \mathrm{m} \text { Merit Medical } \\
\text { embospheres }\end{array}$ \\
\hline BEAT 2019 [29] & Prospective & 20 & 12 months & $7.6 \mathrm{~kg}(11.5 \%)$ & $\begin{array}{c}\text { 300-500 } \mu \mathrm{m} \text { Merit Medical } \\
\text { embospheres }\end{array}$ \\
\hline Zaitun 2019 [30] & $\begin{array}{l}\text { Prospective } \\
\text { (pre-diabetic) }\end{array}$ & 10 & 6 months & $9 \mathrm{~kg}(8.9 \%)$ & $\begin{array}{c}\text { 300-500 } \mu \mathrm{m} \text { Merit Medical } \\
\text { embospheres }\end{array}$ \\
\hline LOSEIT 2020 [31] & $\begin{array}{l}\text { Randomized, } \\
\text { sham-controlled }\end{array}$ & 40 & 12 months & $9.3 \mathrm{Kg}(9.3 \%)$ & $\begin{array}{c}\text { 300-500 } \mu \mathrm{m} \text { BeadBlock } \\
\text { microspheres }\end{array}$ \\
\hline $\begin{array}{l}\text { BEATLES } 2023 \\
\text { [32]On-going Trial }\end{array}$ & $\begin{array}{c}\text { Randomized, } \\
\text { sham-controlled }\end{array}$ & 56 & 12 months & On-going trial & $\begin{array}{l}\text { 100-200 } \mu \text { m radiopaque } \\
\text { microspheres }\end{array}$ \\
\hline
\end{tabular}

\section{Current and Future Perspectives}

Considering the huge impact of obesity in public health worldwide, novel treatments are of utmost importance to reduce associated morbidity and mortality related to this condition and its complications. Early experimental and initial clinical data have suggested that BES may be a promising technique to reduce weight and hormonal imbalance in the obese population. Compared to bariatric surgery, BSE seems to be less invasive, welltolerated, with shorter recovery time, and is probably cost-saving; further randomized clinical trials are needed to confirm this hypothesis and to evaluate eventual consequences regarding metabolic and nutritional status of patients underwent EBS. The duration of BES procedure varies from 80 to $100 \mathrm{~min}$, with a fluoroscopy time of $32 \pm 14 \mathrm{~min}$. Current human clinical evidence shows that bariatric LGA embolization is an effective treatment that is associated with statistically significant weight loss during follow-up. In addition to weight change, some clinical series have also demonstrated a reduction in serum level of ghrelin and/or leptin $[8,11,29,31]$ and in the level of hemoglobin A1c [29,30] and mean total cholesterol [29]; a statistically significant mean decrease in diastolic blood pressure in the embolization arm was observed in one trial [31]. Furthermore, the procedure is associated with improvements in quality-of-life after embolization, especially regarding the domains of physical function, self-esteem, sexual life, and public distress. The most frequent side effects after the procedure are nausea, vomiting and epigastric pain, and minor complications such as transient superficial mucosal ulcers are common after LGA embolization (usually treated with proton pump inhibitors and spontaneous healing within 4 weeks to 3 months without the needed of further hospitalization); only one case of major complications after the procedure (pancreatitis, splenic infarct and late gastric perforation) was reported by Elens et al. [9].

Distal embolizing agents (mostly embospheres and PVA particles) have been the main embolic material used in recent trials. Although bariatric embolization seems to be safe in this initial phase and results in terms of weight loss are promising, we need further data on patients subsequently treated with conventional bariatric surgery (given that the gastroesophageal junction is de-vascularized) to establish if BES can be utilized as bridge-therapy to surgery in this population. The ideal embolic material remains to be elucidated to achieve what seems to be a perfect safety-efficacy balance mostly on the long term. A larger well designed RCT ideally with a sham-controlled group is eagerly expected to establish the future role of BES in favoring weight loss and hormone homeostasis and for prevention of obese-related morbidity and overall mortality. There is also the needed of a trial of comparison between BES and optimal medical therapy, including new drugs 
like Semaglutide [33]. At last there are not data of comparison between BES and surgical techniques to evaluate if BES should be considered as an alternative in those patients who are not passible of surgery (multimorbid patients).

Author Contributions: Conceptualization, G.M.S. and A.C.; Methodology, G.M.S.; Validation, G.M.S., A.C. and N.P.; Formal Analysis, G.M.S., A.C. and G.C.; Investigation, G.M.S., A.C. and G.C.; Data Curation, A.M. and M.B.; Writing-Original Draft Preparation, G.M.S. and N.P.; Writing-Review \& Editing, all authors. Visualization, all authors. Supervision, G.M.S. and N.P.; Project Administration, G.M.S.; Funding Acquisition, G.M.S. All authors have read and agreed to the published version of the manuscript.

Funding: This research received no external funding.

Acknowledgments: Authors wish to thank Sara Sguotti from Medtronic Corporation for her invaluable technical assistance during the procedures and in manuscript preparation. All the authors have consented to the acknowledgement.

Conflicts of Interest: The authors declare no conflict of interest.

\section{References}

1. Flegal, K.M.; Kit, B.K.; Orpana, H.; Graubard, B.I. Association of all-cause mortality with overweight and obesity using standard body mass index categories: A systematic review and meta-analysis. JAMA 2013, 309, 71-82. [CrossRef]

2. Kim, D.D.; Basu, A. Estimating the medical care costs of obesity in the united states: Systematic review, meta-analysis, and empirical analysis. Value Health 2016, 19, 602-613. [CrossRef]

3. Jensen, M.D.; Ryan, D.H.; Apovian, C.M.; Ard, J.D.; Comuzzie, A.G.; Donato, K.A.; Hu, F.B.; Hubbard, V.S.; Jakicic, J.M.; Kushner, R.F.; et al. 2013 AHA/ ACC/TOS guideline for the management of overweight and obesity in adults: A report of the American College of Cardiology/American Heart Association Task Force on Practice Guidelines and the Obesity Society. Circulation 2014, 129, S102-S138. [CrossRef]

4. Lupoli, R.; Lembo, E.; Saldalamacchia, G.; Avola, C.K.; Angrisani, L.; Capaldo, B. Bariatric surgery and long-term nutritional issues. World J. Diabetes 2017, 8, 464-474. [CrossRef]

5. Fujioka, K. Follow-up of nutritional and metabolic problems after bariatric surgery. Diabetes Care 2005, 28, 481-484. [CrossRef] [PubMed]

6. Mangan, A.; Le Roux, C.W.; Miller, N.G.; Docherty, N.G. Iron and Vitamin D/Calcium Deficiency after Gastric Bypass: Mechanisms Involved and Strategies to Improve Oral Supplement Disposition. Curr. Drug Metab. 2019, 20, 244-252. [CrossRef]

7. Di Lorenzo, N.; Antoniou, S.A.; Batterham, R.L.; Busetto, L.; Godoroja, D.; Iossa, A.; Carrano, F.M.; Agresta, F.; Alarçon, I.; Azran, C.; et al. Clinical practice guidelines of the European Association for Endoscopic Surgery (EAES) on bariatric surgery: Update 2020 endorsed by IFSO-EC, EASO and ESPCOP. Surg. Endosc. 2020, 34, 2332-2358. [CrossRef] [PubMed]

8. Bai, Z.-B.; Qin, Y.-L.; Deng, G.; Zhao, G.-F.; Zhong, B.-Y.; Teng, G.-J. Bariatric embolization of the left gastric arteries for the treatment of obesity: 9-month data in 5 patients. Obes. Surg. 2018, 28, 907-915. [CrossRef] [PubMed]

9. Elens, S.; Roger, T.; Elens, M.; Rommens, J.; Sarafidis, A.; Capelluto, E.; Delcour, C. Gastric embolization as treatment for overweight patients; Ef-ficacy and safety. Cardiovasc. Interv. Radiol. 2019, 42, 513-519. [CrossRef]

10. Hafezi-Nejad, N.; Bailey, C.R.; Weiss, C.R. Bariatric embolization: A narrative review of clinical data from human trials. Tech. Vasc. Interv. Radiol. 2020, 23, 100658. [CrossRef]

11. Kipshidze, N.; Archvadze, A.; Bertog, S.; Leon, M.B.; Sievert, H. Endovascular bariatrics: First in humans study of gastric artery embolization for weight loss. JACC Cardiovasc. Interv. 2015, 8, 1641-1644. [CrossRef]

12. Pirlet, C.; Ruzsa, Z.; Costerousse, O.; Nemes, B.; Merkely, B.; Poirier, P.; Bertrand, O.F. Transradial left gastric artery embolization to treat severe obesity: A pilot study. Catheter. Cardiovasc. Interv. 2019, 93, 365-370. [CrossRef]

13. Syed, M.I.; Morar, K.; Shaikh, A.; Craig, P.; Khan, O.; Patel, S.; Khabiri, H. Gastric artery embolization trial for the lessening of appetite nonsurgically (GET LEAN): Six-month preliminary data. J. Vasc. Interv. Radiol. 2016, 27, 1502-1508. [CrossRef]

14. Korbonits, M.; Goldstone, A.P.; Gueorguiev, M.; Grossman, A.B. Ghrelin-A hormone with multiple functions. Front. Neuroendocrinol. 2004, 25, 27-68. [CrossRef] [PubMed]

15. Nakazato, M.; Murakami, N.; Date, Y.; Kojima, M.; Matsuo, H.; Kangawa, K.; Matsukura, S. A role for ghrelin in the central regulation of feeding. Nat. Cell Biol. 2001, 409, 194-198. [CrossRef]

16. Duca, F.A.; Covasa, M. Current and emerging concepts on the role of periperal signals in the control of food intake and development of obesity. Br. J. Nutr. 2012, 108, 778-793. [CrossRef]

17. Page, A.J.; Slattery, J.A.; Milte, C.; Laker, R.; O’Donnell, T.; Dorian, C.; Brierley, S.; Blackshaw, A. Ghrelin selectively reduces mechanosensitivity of upper gastrointestinal vagal afferents. Am. J. Physiol. Liver Physiol. 2007, 292, G1376-G1384. [CrossRef]

18. Gunn, A.J.; Oklu, R. A preliminary observation of weight loss following left gastric artery embolization in humans. J. Obes. 2014, 2014, 185349. [CrossRef] [PubMed] 
19. Kim, D.J.; Raman, H.S.; Salter, A.; Ramaswamy, R.; Gunn, A.J.; Weiss, C.R.; Akinwande, O. Analysis of weight changes after left gastric artery embolization in a cancer-naive population. Diagn. Interv. Radiol. 2018, 24, 94-97. [CrossRef] [PubMed]

20. Arepally, A.; Barnett, B.; Montgomery, E.; Patel, T.H. Catheter-directed gastric artery chemical embolization for modulation of systemic ghrelin levels in a porcine model: Initial experience. Radiology 2007, 244, 138-143. [CrossRef]

21. Arepally, A.; Barnett, B.; Patel, T.T.; Howland, V.; Boston, R.C.; Kraitchman, D.L.; Malayeri, A.A. Catheter-directed gastric artery chemical embolization suppresses systemic ghrelin levels in porcine model. Radiology 2008, 249, 127-133. [CrossRef] [PubMed]

22. Bawudun, D.; Xing, Y.; Liu, W.-Y.; Huang, Y.-J.; Ren, W.-X.; Ma, M.; Xu, X.-D.; Teng, G.-J. Ghrelin suppression and fat loss after left gastric artery em-bolization in canine model. Cardiovasc. Interv. Radiol. 2012, 35, 1460-1466. [CrossRef] [PubMed]

23. Paxton, B.E.; Kim, C.Y.; Alley, C.L.; Crow, J.H.; Balmadrid, B.; Keith, C.G.; Kankotia, R.J.; Stinnett, S.; Arepally, A. Bariatric embolization for suppression of the hunger hormone ghrelin in a porcine model. Radiology 2013, 266, 471-479. [CrossRef] [PubMed]

24. Paxton, B.E.; Alley, C.L.; Crow, J.H.; Burchette, J.; Weiss, C.R.; Kraitchman, D.L.; Arepally, A.; Kim, C.Y. Histopathologic and immunohistochemical sequelae of bar-iatric embolization in a porcine model. J. Vasc. Interv. Radiol. 2014, 25, 455-461. [CrossRef] [PubMed]

25. Paxton, B.E.; Arepally, A.; Alley, C.L.; Kim, C.Y. Bariatric embolization: Pilot study on the impact of gastroprotective agents and arterial distribution on ulceration risk and efficacy in a porcine model. J. Vasc. Interv. Radiol. 2016, 27, 1923-1928. [CrossRef]

26. Kim, J.M.; Kim, M.D.; Han, K.; Muqmiroh, L.; Kim, S.U.; Kim, G.M.; Kwon, J.; Pari, S., Jr.; Won, J.Y.; Lee, D.Y. Bariatric arterial embolization with non-spherical polyvinyl alcohol particles for ghrelin suppression in a swine model. Cardiovasc. Interv. Radiol. 2017, 40, 744-749. [CrossRef]

27. Hafezi-Nejad, N.; Bailey, C.R.; Gunn, A.J.; Weiss, C.R. Weight loss after left gastric artery embolization: A systematic review and meta-analysis. J. Vasc. Interv. Radiol. 2019, 30, 1593-1603.e3. [CrossRef]

28. Fu, Y.; Kraitchman, D.L. Rationale and preclinical data supporting bariatric arterial embolization. Tech. Vasc. Interv. Radiol. 2020, 23, 100656. [CrossRef]

29. Weiss, C.R.; Abiola, G.O.; Fischman, A.M.; Cheskin, L.J.; Vairavamurthy, J.; Holly, B.P.; Akinwande, O.; Nwoke, F.; Paudel, K.; Belmustakov, S.; et al. Bariatric embolization of arteries for the treatment of obesity (BEAT Obesity) trial: Results at 1 year. Radiology 2019, 291, 792-800. [CrossRef]

30. Zaitoun, M.M.; Basha, M.A.A.; Hassan, F.; Elsayed, S.B.; Farag, A.A.; Amer, M.; Aly, S.A.; Zaitoun, N. Left gastric artery embolization in obese, prediabetic patients: A pilot study. J. Vasc. Interv. Radiol. 2019, 30, 790-796. [CrossRef] [PubMed]

31. Reddy, V.Y.; Neužil, P.; Musikantow, D.; Sramkova, P.; Rosen, R.; Kipshidze, N.; Kipshidze, N.; Fried, M. Transcatheter bariatric embolotherapy for weight reduction in obesity. JACC 2020, 76, 2305-2317. [CrossRef] [PubMed]

32. Weiss, C.R.; Abiola, G.O.; Fischman, A.M.; Cheskin, L.J.; Vairavamurthy, J.; Holly, B.P.; Akinwande, O.; Nwoke, F.; Paudel, K.; Belmustakov, S.; et al. Bariatric embolization of arteries with imaging visible embolics (BEATLES) (BAE2). Clin. Trials.

33. Davies, M.; Færch, L.; Jeppesen, O.K.; Pakseresht, A.; Pedersen, S.D.; Perreault, L.; Rosenstock, J.; Shimomura, I.; Viljoen, A.; Wadden, T.A.; et al. Semaglutide $2.4 \mathrm{mg}$ once a week in adults with overweight or obesity, and type 2 diabetes (STEP 2): A randomised, double-blind, double-dummy, placebo-controlled, phase 3 trial. Lancet 2021, 397, 971-984. [CrossRef] 